\title{
Fitossociologia de plantas daninhas em função de diferentes manejos de coberturas de inverno
}

\author{
Phytosociology of weeds in function of different managements of winter cover \\ Tadeu Werlang ${ }^{1 *}$, Ana Caroline Pereira da Luz, Vinícius Cavalli Pozzo ${ }^{1}$, Lucas Andrey \\ Schwerz ${ }^{1}$, Siumar Pedro Tironi ${ }^{1}$, Evandro Franz ${ }^{1}$
}

Resumo - Para aumentar a eficiência do uso das coberturas de solo é importante conhecer quais espécies apresentam maior supressão de plantas daninhas e se o método de manejo das coberturas afeta o efeito de supressão. Objetivou-se, com esse trabalho, avaliar o efeito supressivo de diferentes coberturas de inverno e de diferentes manejos dessas coberturas através de índices fitossociológicos. Para isso conduziu-se um experimento em esquema fatorial $4 \times 3$, em um delineamento experimental de blocos casualizados, com quatro repetições. $\mathrm{O}$ primeiro fator foi constituído por diferentes espécies de cobertura de solo: aveia branca (Avena sativa), nabo (Raphanus raphanistrum), ervilhaca (Vicia sativa) e pousio; o segundo fator foi constituído pelos manejos de cobertura: controle químico, acamamento e sem manejo. No momento do manejo das coberturas foi quantificada a massa seca das mesmas. A comunidade infestante foi avaliada aos 75 dias após o manejo das coberturas, com avaliação do número de plantas daninhas, massa seca de plantas daninhas, frequência relativa, densidade relativa, dominância relativa e índice de valor de importância (IVI). A aveia produz a maior quantidade de massa seca. A comunidade infestante é composta por 31 espécies. No manejo químico, as coberturas de aveia e ervilhaca são as que mais suprimem o número de plantas daninhas. De modo geral, a dessecação promove maior número de plantas daninhas, porém diminui a massa seca das mesmas. As espécies Spermacoce latifolia, Conyza bonariensis e Sida rhombifolia apresentam elevados valores de IVI. A dessecação das coberturas favorece espécies tolerantes a herbicidas a se sobressaírem no ambiente.

Palavras-chave: aveia, acamamento, ervilhaca, glyphosate, nabo

\begin{abstract}
In order to increase the efficiency of the use of cover crops, it is important to know which species present the greatest suppression of weeds and if the cover crop management method affects the suppression effect. The goal, with this work, was to evaluate the suppressive effect of different winter cover crops and their different managements through the use of phytosociological indices. The experimental design used was of randomized blocks conducted in a $4 \times 3$ factorial scheme with four replicates. The first factor was constituted by different cover crop species: white oats (Avena sativa), wild radish (Raphanus raphanistrum), vetch (Vicia sativa) and fallow; the second factor was constituted by the cover crop management: chemical control, lodging and no management. The dry matter of the cover crops was quantified at the moment of cover crop management. The weed community was evaluated 75 days after the cover crop management took place, with the
\end{abstract}


Recebido: Novembro 28, 2017. Aceito: Junho 22, 2018.

${ }^{1}$ Universidade Federal da Fronteira Sul - UFFS, SC-484 km 02, CEP 89815-899, Chapecó; SC, Brasil. E-mail: tadeuwerlang@gmail.com; anacarolinebera@hotmail.com; vinicius_pozzo@hotmail.com, lucas.schwerz1994@gmail.com; siumar.tironi@gmail.com; franzevandro@gmail.com

assessment of the number of weeds, weed dry matter, relative frequency, relative density, relative dominance, and importance value index (IVI). Oats produces the greatest amount of dry matter. The weed community is compos of 31 species. In the chemical management, oat and vetch cover crops are the ones that suppress the greatest number of weeds. In general, the desiccation allow to a greater number of weeds, but with decrease dry matter. The species Spermacoce latifolia, Conyza bonariensis and Sida rhombifolia present high IVI values. The desiccation of the cover crops may favor herbicide-tolerant species which excel in the environment. Keywords: oats, lodging, vetch, glyphosate, wild radish

\section{Introdução}

Atualmente as plantas daninhas são manejadas predominantemente pelo controle químico, com uso de herbicidas, porém o uso inadequado desse método pode ocasionar sérios riscos ao ambiente (Balbinot Junior et al., 2007). Uma prática adotada por muitos agricultores da região sul do Brasil é deixar a lavoura em pousio durante o período de inverno, mas, nessas áreas a incidência de plantas daninhas é elevada, enriquecendo o banco de sementes, acarretando em uma nova infestação de plantas daninhas no cultivo seguinte (Lima et al., 2014).

Uma prática que pode contribuir para o controle de plantas daninhas é o cultivo de plantas de cobertura no período de inverno e a realização de semeadura direta em sucessão, com a manutenção da palhada sobre o solo. A utilização de plantas de cobertura reduz o banco de sementes de plantas daninhas no solo (Sodré Filho et al., 2008) e também o estabelecimento dessas espécies, exercendo um efeito físico, interferindo na germinação e na taxa de sobrevivência das plântulas de algumas plantas daninhas (Monquero et al., 2009).

Dentre as coberturas de inverno mais utilizadas no sul do Brasil estão a aveia (Avena sativa), a ervilhaca (Vicia sativa) e o nabo (Raphanus raphanistrum). A aveia tem alto potencial em acumular matéria seca (Balbinot Junior et al., 2007) o que é uma característica importante, pois a supressão de plantas daninhas ocorre de forma linear com a quantidade de palha produzida pela cobertura (Hoshino et al., 2017). A ervilhaca e o nabo também apresentam efeitos supressivos sobre diversas espécies daninhas (Cutti et al., 2016; Martins et al., 2016).

O controle químico, com a dessecação das espécies de cobertura pode reduzir o número de plantas daninhas da área (Moraes et al., 2009) no entanto, a utilização de herbicidas como o glyphosate, de forma frequente, pode modificar a composição de plantas daninhas na área (Santos et al., 2015) em que plantas tolerantes ou resistentes a esses herbicidas podem se sobressair no ambiente ocorrendo mudanças na flora infestante (Moreira et al., 2010). Outros métodos de manejo das coberturas devem ser testados, verificando se afetam a capacidade de supressão de plantas daninhas.

Os estudos fitossociológicos são métodos de avaliação ecológica que objetivam fornecer uma visão abrangente da composição e da distribuição das espécies em uma comunidade vegetal, permitindo a identificação das espécies daninhas mais importantes em uma área, através do levantamento das espécies que apresentam o maior número de indivíduos, amplamente distribuídos e capazes de dominar as outras espécies através do acúmulo de massa (Concenço et al., 2013).

Algumas plantas daninhas podem se estabelecer mesmo em áreas com coberturas de solo, como as espécies Ipomoea grandifolia, Euphorbia heterophylla, Digitaria sanguinalis e Cyperus rotundus que se estabeleceram mesmo 
sobre efeito das coberturas de aveia, nabo, azevém e ervilhaca (Cutti et al., 2016). Em pesquisa envolvendo 26 coberturas de verão, as espécies Raphanus spp. e Conyza bonariensis se desenvolveram em áreas em que a cobertura não foi eficiente (Lamego et al., 2015).

Desse modo, este estudo foi desenvolvido com o objetivo de avaliar o efeito supressivo das coberturas de inverno aveia, nabo, ervilhaca e pousio e de diferentes manejos das coberturas através de índices fitossociológicos.

\section{Material e métodos}

O presente trabalho foi conduzido a campo no ano agrícola de 2015/2016. De acordo com a classificação de Köppen, o clima da região é classificado como subtropical Cfa e os dados climáticos observados durante o período do experimento foram obtidos no Instituto Nacional de Meteorologia (INMET) (Figura 1).

O solo da área é classificado como um Latossolo Vermelho de textura argilosa. A análise química do solo da camada arável (0-20 $\mathrm{cm})$ apresentou os seguintes valores: $\mathrm{pH}\left(\mathrm{H}_{2} \mathrm{O}\right)$ : 5,9; Matéria orgânica: $5,00 \mathrm{~g} \mathrm{~kg}^{-1}$; Fósforo: 8,00 $\mathrm{mg} \mathrm{dm}{ }^{-3}$;

Potássio: $165,60 \mathrm{mg} \mathrm{dm}{ }^{-3} ; \mathrm{H}^{+}+\mathrm{Al}^{3+}: 3,47 \mathrm{cmol}$ $\mathrm{dm}^{-3} ; \mathrm{Al}^{3+}: 0,00 \mathrm{cmol} \mathrm{dm}^{-3} ; \mathrm{Ca}^{2+}: 5,70 \mathrm{cmol} \mathrm{dm}^{-}$ 3. $\mathrm{Mg}^{2+}: 3,70 \mathrm{cmol} \mathrm{dm}^{-3} ; \mathrm{CTC}_{\text {total. }}: 13,29 \mathrm{cmol} \mathrm{dm}^{-}$ ${ }^{3}$ e V: $73,92 \%$.

$\mathrm{O}$ experimento foi conduzido em esquema fatorial $4 \times 3$, com quatro repetições em delineamento de blocos casualizados. O

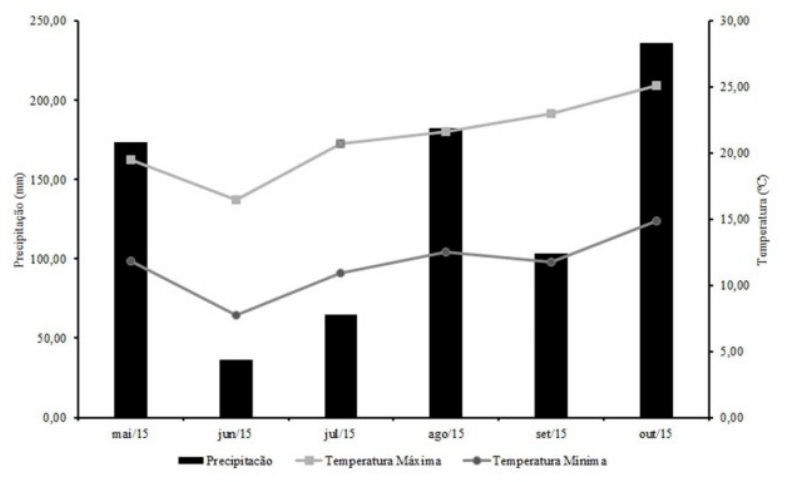

primeiro fator foi constituído por diferentes espécies de cobertura de solo, sendo elas: aveia (Avena sativa), nabo (Raphanus raphanistrum), ervilhaca (Vicia sativa) e pousio, o segundo fator foi constituído por diferentes métodos de manejo da cobertura, com controle químico, acamamento e sem manejo. Os tratamentos foram alocados em parcelas de $18 \mathrm{~m}^{2}(3 \times 6 \mathrm{~m})$.

Para a semeadura das espécies de cobertura foi realizado o preparo convencional do solo, com aração e gradagem. As espécies foram semeadas manualmente à lanço e incorporadas ao solo com uma gradagem. Para a semeadura da aveia, nabo e ervilhaca, foram utilizadas quantidades equivalentes à 80,15 e $60 \mathrm{~kg} \mathrm{ha}^{-1}$, respectivamente, para cada espécie vegetal.

As espécies de cobertura se desenvolveram sem a realização de adubação e sem controle de plantas daninhas. No período de pleno florescimento das coberturas foi realizada a quantificação do acúmulo de massa dessas espécies, com a análise da massa seca da parte aérea (MSPA-PC) das mesmas. Para a determinação dessa variável foram realizadas quatro amostragens por parcela, totalizando dezesseis quadrados por tratamento, utilizando um quadrado vazado de $0,5 \times 0,5 \mathrm{~m}$, lançado aleatoriamente dentro da área útil de cada parcela, desconsiderando $0,5 \mathrm{~m}$ das bordas de cada parcela. As plantas de cobertura foram cortadas rente ao solo e a parte aérea foi coletada. Posteriormente, o material vegetal foi alocado em sacos de papel e levadas a estufa de

Figura 1. Dados climáticos no período da realização do estudo, de maio/2015 a outubro/2015.

Fonte: INMET (2017).

circulação forçada de ar a $60{ }^{\circ} \mathrm{C}$ até atingirem peso constante. A mensuração da massa seca foi realizada com balança semi-analítica e estimada a MSPA-PC $\left(\mathrm{kg} \mathrm{ha}^{-1}\right)$. 
O manejo das espécies de cobertura foi realizado logo após a coleta da massa das plantas (pleno florescimento). O manejo químico foi realizado por meio da aplicação de glyphosate potássico (Zapp QI $\mathrm{Q}^{\square}, 620 \mathrm{~g} \mathrm{~L}^{-1}$ i.a., SL, Syngenta), na dose de 1364 g i.a. ha ${ }^{-1}$ em associação com 2,4-D amina (DMA ${ }^{\square} 806$ BR, $806 \mathrm{~g} \mathrm{~L}^{-1}$ i.a., SL, Dow AgroSciences), na dose de 1209 g i.a. ha-1 . As aplicações dos herbicidas foram realizadas com um pulverizador costal de precisão, calibrado para aplicar um volume de $150 \mathrm{~L} \mathrm{ha}^{-1}$ de calda.

$\mathrm{O}$ acamamento das espécies foi realizado com o auxílio de rolo-faca.

Aos 75 dias após a realização do manejo das espécies de cobertura foi realizado o levantamento fitossociológico da comunidade infestante, onde foram realizadas quatro amostragens por parcela, para isso, utilizou-se um quadrado vazado de $0,5 \times 0,5 \mathrm{~m}$ de lado lançado aleatoriamente no interior da área útil de cada parcela. As plantas daninhas contidas dentro dos quadrados foram coletadas, identificadas e quantificadas, de acordo com Kissmann e Groth (1995, 1997, 1999). Posteriormente foram alocadas em sacos de papel e levadas a estufa de circulação forçada de ar à $60^{\circ} \mathrm{C}$ até atingirem peso constante, para a determinação da massa seca da parte aérea das plantas daninhas (MSPA-PD).

Após a contagem do número de plantas daninhas (NPD) e identificação das espécies foram calculados os seguintes parâmetros fitossociológicos: frequência $(F)$, frequência relativa (FR), densidade (D), densidade relativa (DR), e a dominância relativa (DoR), a fim de obter o índice de valor de importância (IVI) determinados de acordo com as equações propostas por Mueller-Dombois e Ellenberg (1974).

Os dados foram submetidos à análise de variância $(p<0,05)$, em que foi avaliada a significância e a interação entre os fatores. As médias das variáveis que apresentaram significância foram comparadas pelo teste de Tukey. Os dados relativos à fitossociologia de plantas daninhas foram analisados de forma descritiva.

\section{Resultados e discussão}

A aveia foi a cobertura que apresentou maior acúmulo de biomassa, como observado na variável MSPA-PC, seguido do nabo e da ervilhaca, as quais não diferiram entre si, e pelo pousio (Tabela 1). A aveia é uma das espécies de cobertura que apresentam elevado acúmulo de biomassa (Cutti et al., 2016), possivelmente pela elevada capacidade de perfilhamento e crescimento da mesma. A quantidade de palha produzida consiste em característica importante para uma espécie de cobertura de solo, pois quanto maior a palhada maior será seu efeito supressivo sobre as plantas daninhas (Hoshino et al., 2017).

A composição da comunidade de plantas daninhas na área foi considerada heterogênea. Ao todo foram coletadas 31 espécies, sendo 20 eudicotiledôneas e 11 monocotiledôneas, distribuídas em 14 famílias botânicas, destacando-se as famílias Poaceae e Asteraceae, em que ambas corresponderam a, aproximadamente, $55 \%$ das espécies (Tabela 2). As famílias botânicas Poaceae e Asteraceae frequentemente são apontadas como os principais grupos de plantas daninhas quanto ao número de espécies (Maciel et al., 2010; Santos et al., 2016).

Houve interação entre os fatores estudados para o NPD (plantas $\mathrm{m}^{-2}$ ). No entanto, as coberturas não influenciaram no NPD nos tratamentos sem manejo e acamamento (Figura 2). No manejo químico, a aveia e a ervilhaca foram as coberturas que mais suprimiram o NPD, porém, não diferindo do nabo, sendo que essa espécie foi igual ao tratamento com pousio (Figura 2). A cobertura de aveia (598 plantas m 
${ }^{2}$ ) e a ervilhaca (611 plantas $\mathrm{m}^{-2}$ ) apresentaram $41 \%$ e $39 \%$ de supressão maior, respectivamente, do estabelecimento das espécies infestantes que o tratamento pousio (1006 plantas $\mathrm{m}^{-2}$ ).

Outros estudos também relataram maior NPD quando a área foi deixada em pousio (Martins et al., 2016) e na cobertura de nabo (Cutti et al., 2016)

Tabela 1. Massa seca da parte aérea (MSPAPC) das coberturas de inverno, aveia, nabo, ervilhaca e pousio $\left(\mathrm{t} \mathrm{ha}^{-1}\right)$.

\begin{tabular}{cc}
\hline Cobertura Vegetal & $\begin{array}{c}\text { Massa seca das } \\
\text { coberturas t ha } \mathbf{~ h}^{-1}\end{array}$ \\
\hline Aveia & $5,22 * \mathrm{a}$ \\
Nabo & $2,37 \mathrm{~b}$ \\
Ervilhaca & $1,85 \mathrm{~b}$ \\
Pousio & $0,67 \mathrm{c}$ \\
\hline
\end{tabular}

*Médias seguidas por letras iguais na coluna, não diferem significativamente pelo teste de Tukey a $5 \%$ de probabilidade.

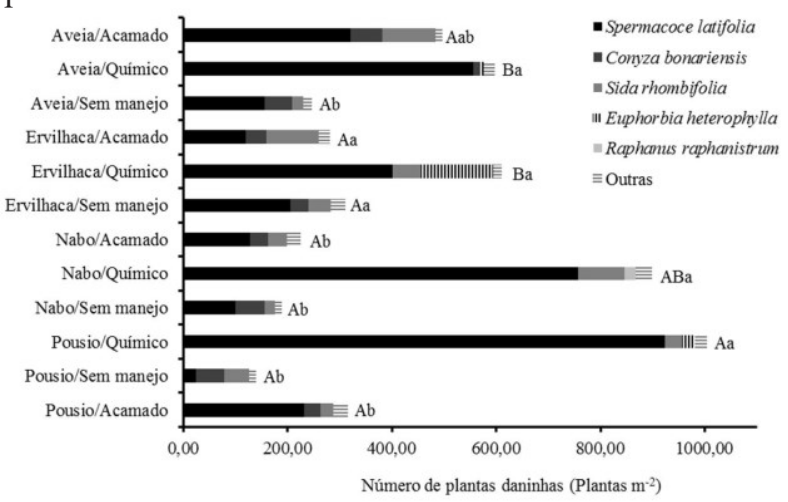


Tabela 2. Diversidade botânica de plantas daninhas coletadas no local do estudo.

\begin{tabular}{|c|c|c|c|}
\hline Classes & Família botânica & Nome científico & Nome comum \\
\hline \multirow[t]{20}{*}{ Eudicotiledônea } & Amaranthaceae & Amaranthus retroflexus & Caruru \\
\hline & Asteraceae & Bidens pilosa & Picão preto \\
\hline & & Bidens subalternans & Picão preto \\
\hline & & Conyza bonariensis & Buva \\
\hline & & Emilia coccínea & Falsa serralha \\
\hline & & Gamochaeta coarctata & Macela \\
\hline & & Mikania cordifolia & Cipó d'água \\
\hline & & Sonchus oleraceus & Serralha \\
\hline & & Vernonia tweediana & Mata pasto \\
\hline & Brassicaceae & Raphanus raphanistrum & Nabo \\
\hline & Convolvulaceae & Ipomoea triloba & Corda de viola \\
\hline & & Ipomoea indivisa & Corda de viola \\
\hline & Euphorbiaceae & Euphorbia heterophylla & Leiteiro \\
\hline & Fabaceae & Vicia villosa & Ervilhaca \\
\hline & Malvaceae & Sida rhombifolia & Guanxuma \\
\hline & Phyllantaceae & Phyllanthus niruri & Quebra pedra \\
\hline & Portulacaceae & Talinum triangulare & Erva gorda \\
\hline & Rubiaceae & Richardia brasiliensis & Poaia branca \\
\hline & & Spermacoce latifolia & Poaia \\
\hline & Solanaceae & Solanum americanum & Maria pretinha \\
\hline \multirow[t]{11}{*}{ Monocotiledônea } & Commelinaceae & Commelina communis & Trapoeraba \\
\hline & Cyperaceae & Cyperus surinamensis & Tiririca \\
\hline & Poaceae & Andropogon bicornis & Rabo de burro \\
\hline & & Avena sativa & Aveia \\
\hline & & Brachiaria plantaginea & Papuã \\
\hline & & Brachiaria brizantha & Capim Marandu \\
\hline & & Digitaria horizontalis & Capim colchão \\
\hline & & Digitaria insularis & Capim amargoso \\
\hline & & Paspalum paniculatum & Grama touceira \\
\hline & \multicolumn{2}{|c|}{ 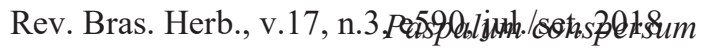 } & Capim ferro \\
\hline & & Setaria geniculata & Rabo de raposa \\
\hline
\end{tabular}


Figura 2. Número de plantas daninhas (NPD) (Plantas $\mathrm{m}^{-2}$ ). Colunas seguidas de mesmas letras, maiúsculas representando o efeito das coberturas e minúsculas representando os manejos das coberturas, não diferem entre si pelo teste de Tukey $(\mathrm{p}<0,05)$.

A menor quantidade de NPD encontradas em sucessão às coberturas de aveia e ervilhaca são resultados do efeito supressivo da palhada dessas espécies, que apresentam elevado acúmulo de biomassa (Balbinot Junior et al., 2007; Cutti et al., 2016). A aveia acumula elevada quantidade de matéria seca, além de possuir baixa velocidade de decomposição da palha devido a elevada relação $\mathrm{C} / \mathrm{N}$ da mesma, mantendo assim o solo coberto por maior período de tempo (Balbinot Junior et al., 2007), exercendo efeitos físicos sobre as sementes de plantas daninhas, interferindo na sua germinação e no estabelecimento das mesmas (Monquero et al., 2009).

Com relação aos métodos de manejo, o controle químico e acamamento acarretaram em maior NPD na cobertura de aveia. Para os tratamentos, cobertura de nabo e pousio, o manejo químico proporcionou aumentos no NPD de $79 \%$ e $86 \%$ respectivamente, em comparação ao tratamento sem manejo. Esses resultados divergem de Moraes et al. (2009), em que a dessecação da cobertura com glyphosate e paraquat reduziram o NPD. Quanto à cobertura de ervilhaca, não houve diferença no NPD entre os manejos realizados (Figura 2).

$\mathrm{O}$ maior NPD nos tratamentos em que as coberturas foram dessecadas pode estar relacionado com a antecipação da morte das plantas de cobertura, pela ação dos herbicidas, assim, acelerando a sua decomposição e diminuindo o efeito de supressão de plantas daninhas proporcionado pela palhada. No tratamento onde as coberturas não foram manejadas a decomposição ocorreu mais lentamente, pois as plantas conseguiram completar o seu ciclo. Com a manutenção de maior quantidade de palha ao longo do tempo há maior supressão das espécies daninhas, pois a massa da cobertura de solo está diretamente correlacionada com seu potencial de supressão de plantas daninhas (Borges et al., 2014).

Outro fator que pode ter contribuído para o elevado NPD no manejo com dessecação foi a grande quantidade de plantas da espécie Spermacoce latifolia, chegando a 924 plantas $\mathrm{m}^{-}$ ${ }^{2}$ no tratamento de dessecação no pousio. Essa espécie é conhecida por ser tolerante a herbicidas (Pacheco et al., 2016), especialmente ao glyphosate, fazendo com que a dessecação apresentasse pouca eficiência sobre a planta daninha, o que proporcionou condições favoráveis ao seu estabelecimento.

Houve interação entre os fatores estudados para a análise da MSPA-PD ( $\mathrm{kg} \mathrm{ha-1})$. No manejo químico observou-se que a cobertura de aveia proporcionou menor acúmulo de MSPAPD, porém não diferindo da cobertura de ervilhaca. Quanto aos tratamentos, acamamento da cobertura e sem manejo, observou-se que a cobertura do

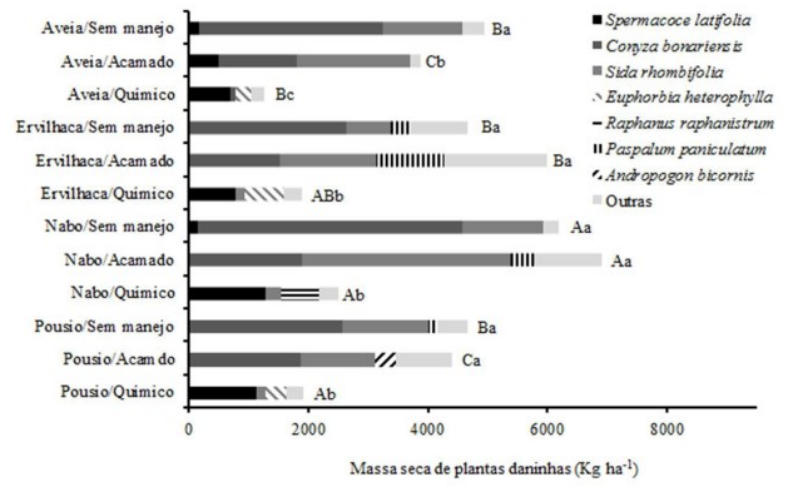

Figura 3. Massa seca da parte aérea das plantas daninhas (MSPA-PD) (kg ha- $\left.{ }^{-1}\right)$ Colunas seguidas de mesmas letras, maiúsculas representando o efeito das coberturas e minúsculas representando os manejos das coberturas, não diferem entre si pelo teste de Tukey $(p<0,05)$. 
nabo proporcionou $44 \%$ e $20 \%$, respectivamente, maior incremento de MSPAPD em comparação com a aveia (Figura 3).

$\mathrm{O}$ maior incremento de MSPA-PD na cobertura de nabo pode estar relacionado com a baixa relação $\mathrm{C} / \mathrm{N}$ de sua palhada, que facilita $\mathrm{e}$ acelera seu processo de degradação, aumentando a disponibilidade de nitrogênio após a mineralização da palhada (Viola et al., 2013), podendo esse nutriente ser utilizado pelas plantas daninhas.

$\mathrm{O}$ manejo químico proporcionou o menor incremento de MSPA-PD independente da cobertura (Figura 3). Observa-se que nos tratamentos, acamamento e sem manejo, houve elevado acúmulo de massa seca, principalmente pela espécie Conyza bonariensis, o que não ocorreu no manejo com dessecação, pois a espécie C. bonariensis é controlada pela aplicação de glyphosate + 2,4-D (Oliveira Neto et al., 2010).

A aplicação de herbicidas como o glyphosate e o uso de diferentes padrões desse herbicida podem exercer influência na composição florística das plantas daninhas (Santos et al., 2015) em que espécies resistentes ou tolerantes, como S. latifolia (Pacheco et al., 2016) podem se sobressair no ambiente.

Analisando o IVI no tratamento com dessecação, destaca-se a espécie $S$. latifolia que apresentou o maior valor, independente da cobertura utilizada, chegando a um IVI de 175 nos tratamentos cobertura de aveia e pousio. $\mathrm{O}$ alto IVI dessa espécie esta relacionado com os altos valores de DR (Figura 4), esse parâmetro é relativo à quantidade de plantas por área (Concenço et al., 2013).

Quando as coberturas foram acamadas, as espécies C. bonariensis, S. latifolia e Sida 


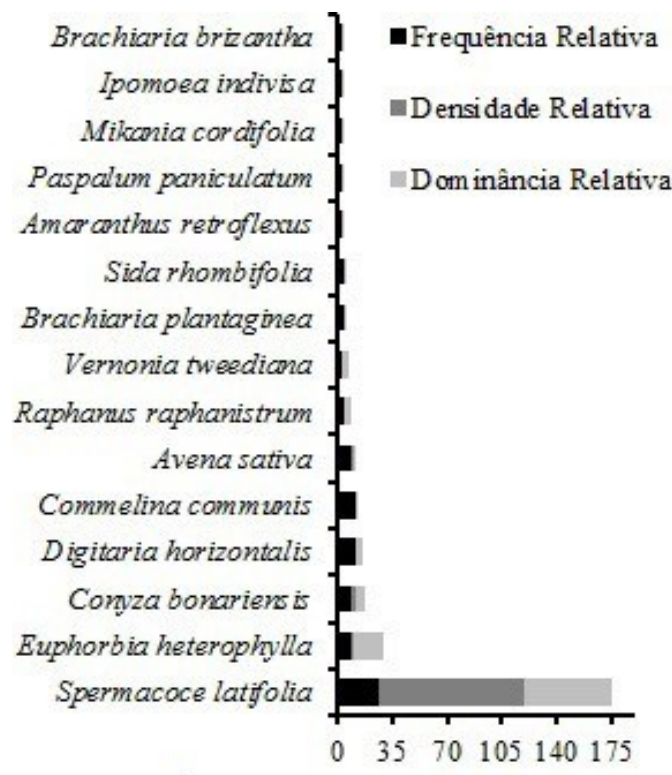

A Índice de valor de importância

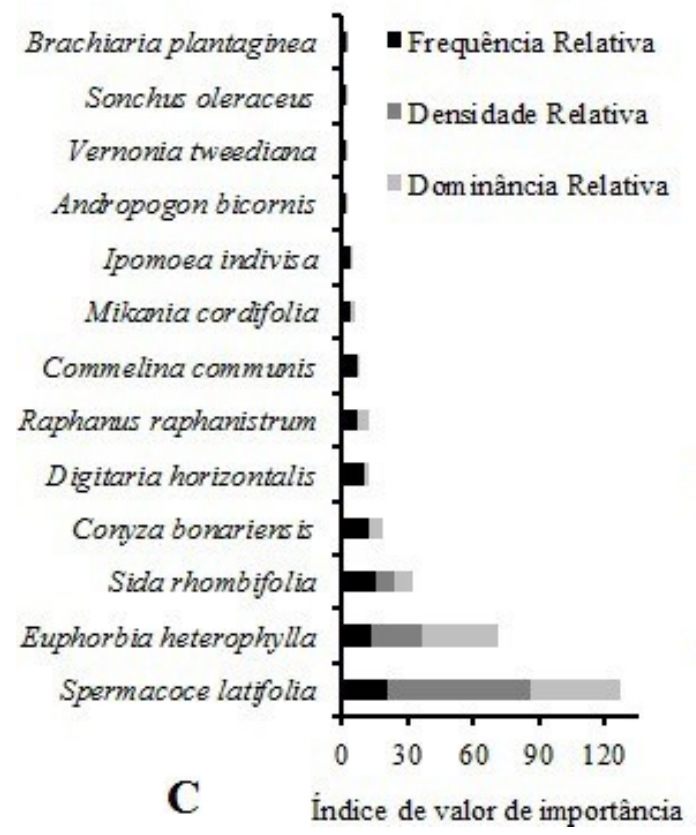

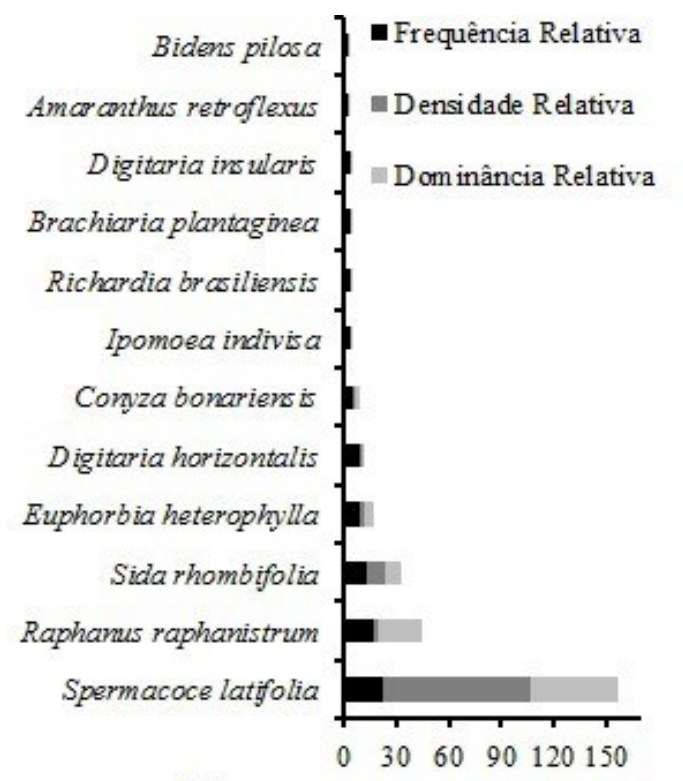

B Índice de valor de importância

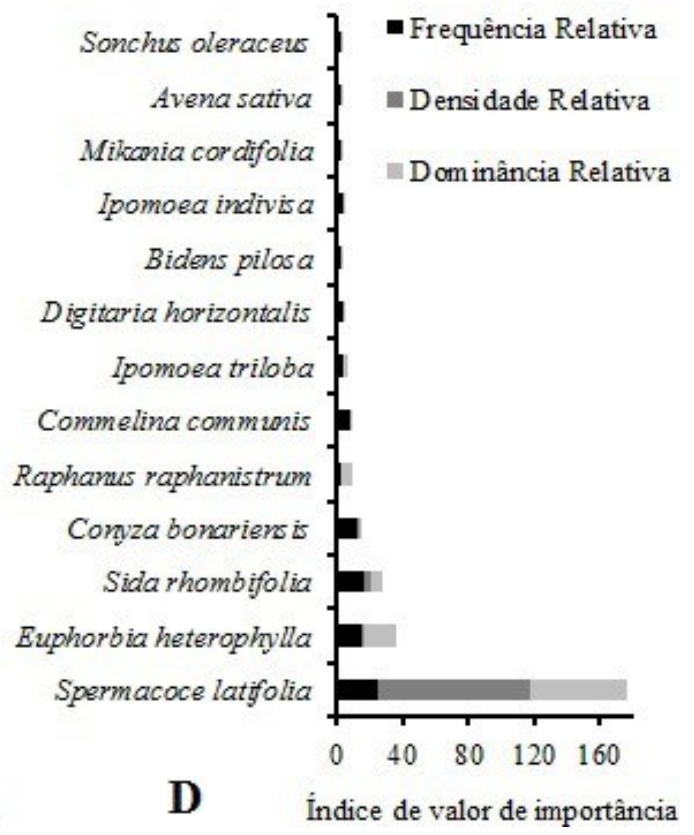

Figura 4. Índice de valor de importância (IVI) das espécies daninhas no manejo dessecação das coberturas, aveia (A), nabo (B), ervilhaca (C) e pousio (D). 

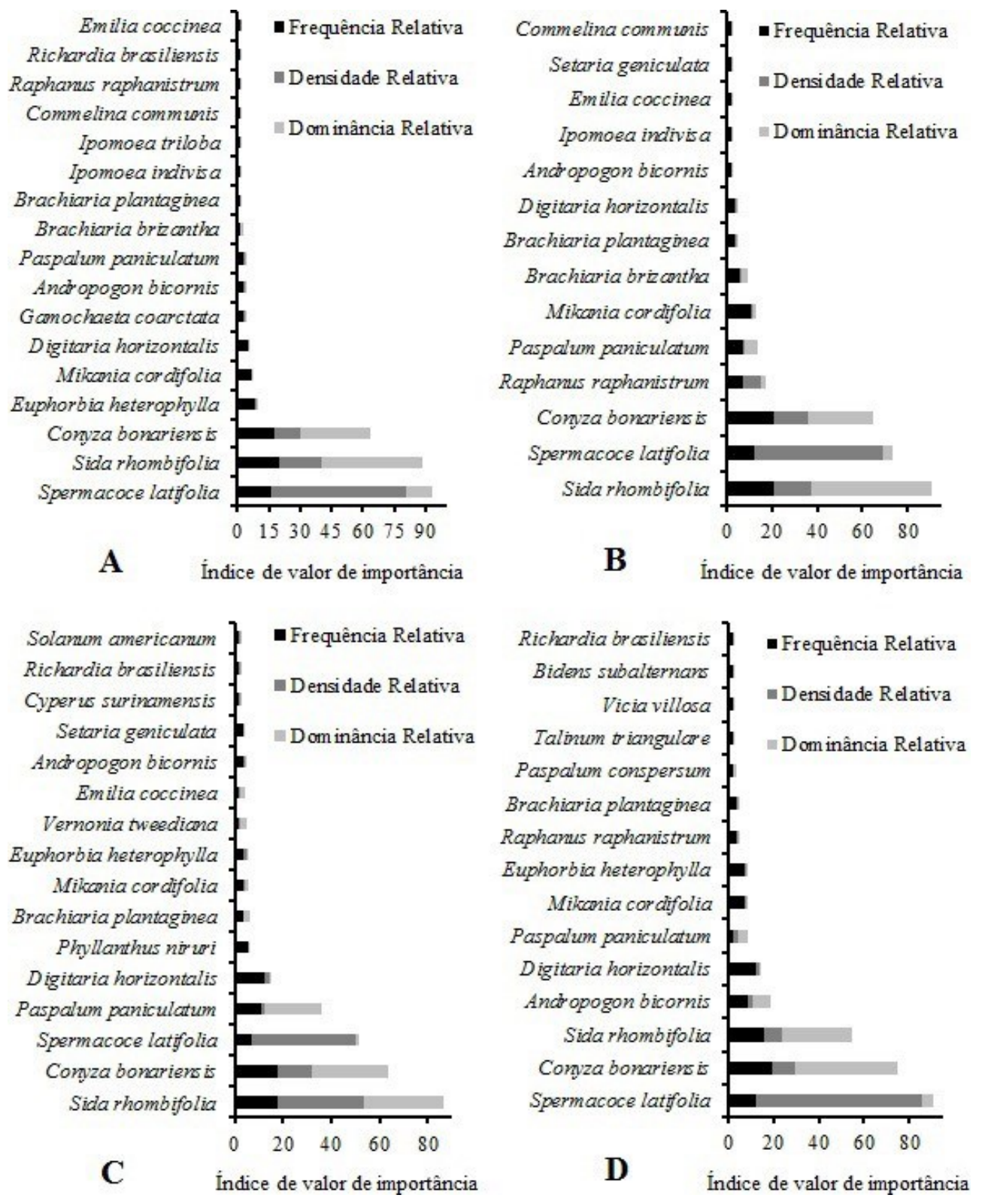

Figura 5. Índice de valor de importância (IVI) das espécies daninhas no manejo acamamento das coberturas, aveia (A), nabo (B), ervilhaca (C) e pousio (D).

rhombifolia obtiveram valores de IVI elevados e de um rápido crescimento e acúmulo de massa muito próximos, independente das plantas de (Concenço et al., 2013). Santos et al. (2016) cobertura utilizadas (Figura 5). A espécie $S$. também relataram que a espécie $C$. bonariensis latifolia se destacou novamente devido seus se destacou por apresentar alto valor de altos valores de DR. As plantas daninhas $C$. dominância. bonariensis e $S$. rhombifolia se destacaram principalmente pelos seus altos valores de DoR, esse índice está relacionado com a habilidade da espécie em suprimir as outras espécies através 
Quando as coberturas não foram manejadas a espécie que apresentou os maiores valores de IVI foi $C$. bonariensis, independente da cobertura utilizada, chegando a um IVI de 120

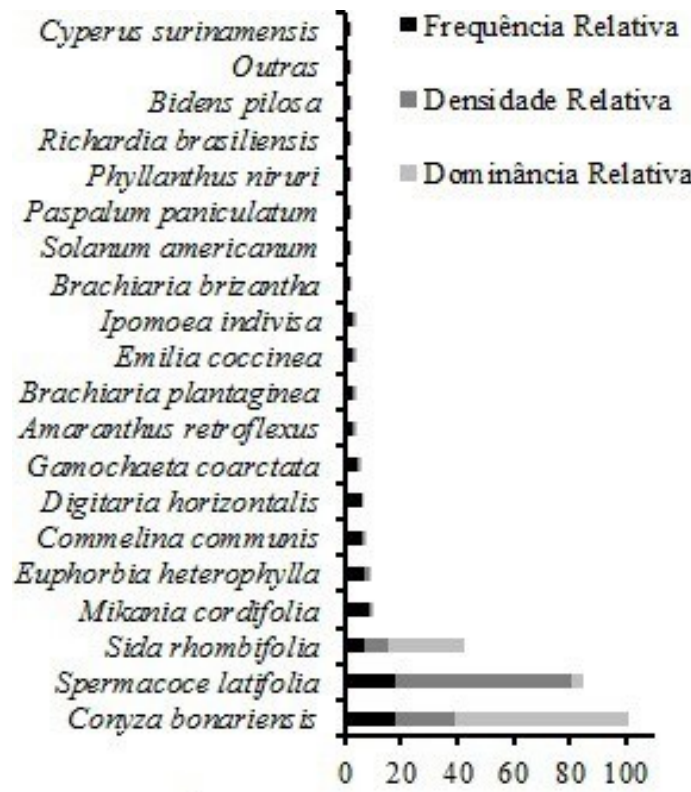

A Índice de valor de importância

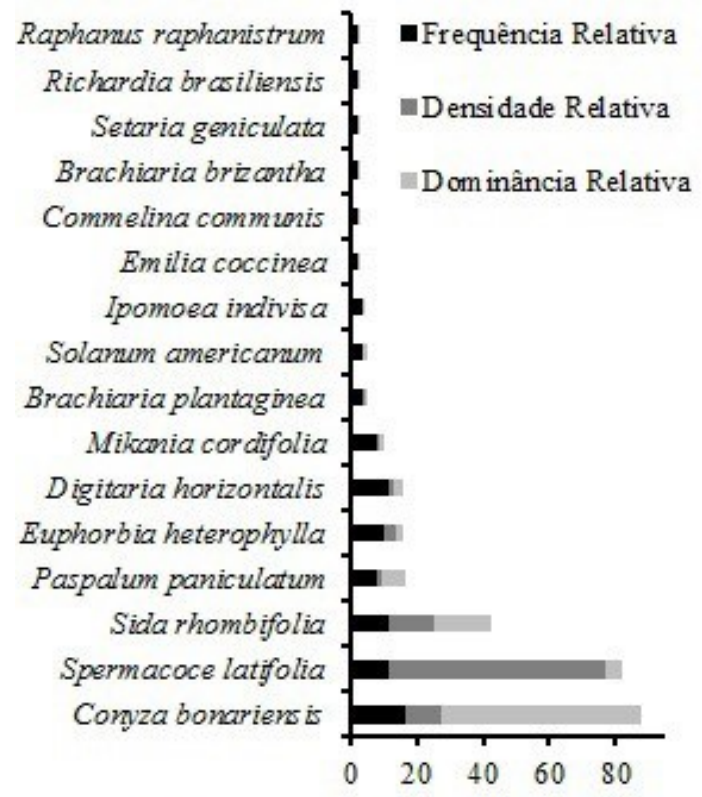

C Indice de valor de importância também se destacaram foram $S$. latifolia e $S$. rhombifolia (Figura 6).

A espécie daninha $S$. latifolia tem como característica que a germinação de suas
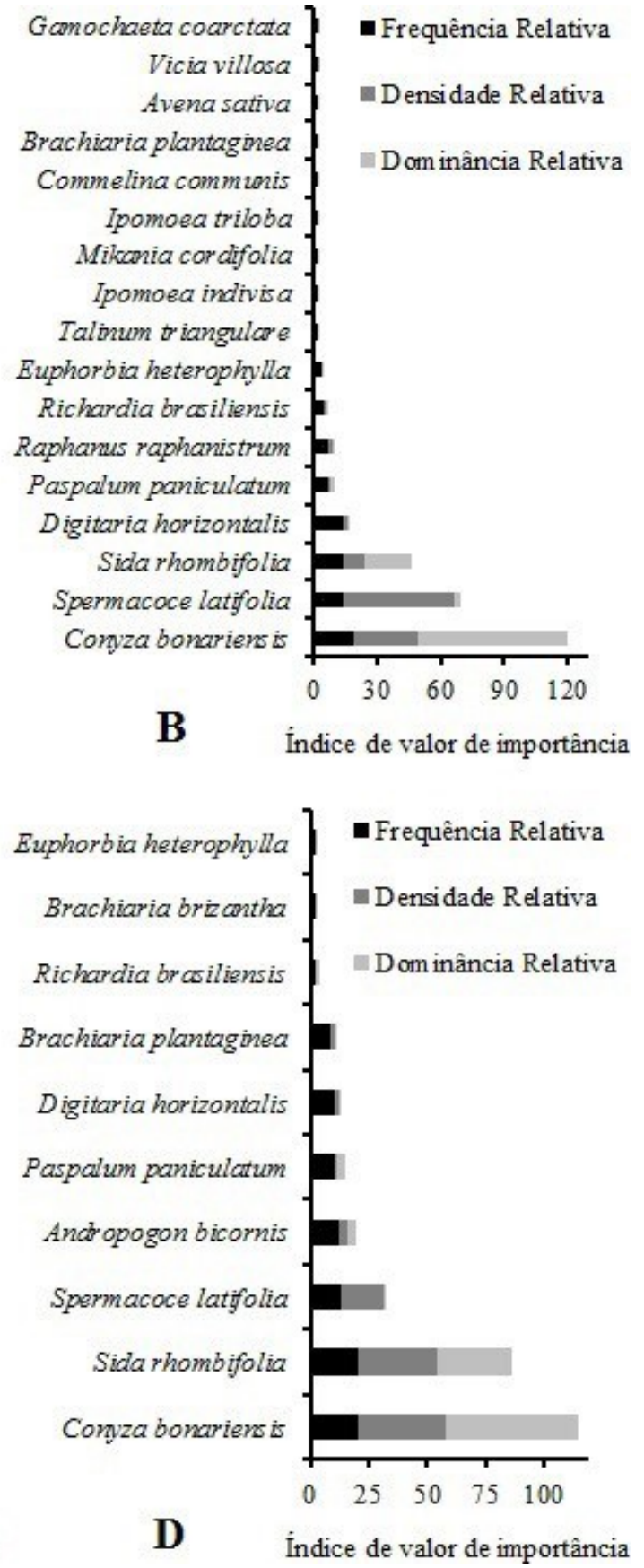

Figura 6. Índice de valor de importância (IVI) das espécies daninhas no tratamento sem manejo das coberturas, aveia (A), nabo (B), ervilhaca (C) e pousio (D). na cobertura de nabo, outras espécies que sementes é indiferente a presença de luz (Parreira et al., 2011). 
Essa característica combinada a sua tolerância a certos herbicidas e seu elevado potencial competitivo (Pacheco et al., 2016) explica o elevado valor de IVI da espécie independente do manejo adotado e da cobertura utilizada.

As espécies que tiveram elevados valores de IVI podem ser consideradas as plantas daninhas mais importantes na área (Concenço et al., 2013), para essas espécies devem ser elaboradas alternativas de manejo, pois se essas espécies estivessem convivendo com alguma cultura de interesse, certamente iriam competir pelos recursos limitantes, tais como, água, luz e nutrientes (Tironi et al., 2014).

\section{Conclusões}

A aveia e a ervilhaca, no manejo dessecação, são as coberturas que mais suprimem a emergência de plantas daninhas. Porém, a dessecação do nabo e do pousio proporciona um aumento no NPD, principalmente da espécie $S$. latifolia.

$\mathrm{O}$ manejo químico proporciona o menor incremento de MSPA-PD independente da cobertura.

A espécie $S$. latifolia apresenta elevados valores de IVI independente do manejo adotado ou da cobertura utilizada. Destacam-se também as espécies $C$. bonariensis e $S$. rhombifolia no manejo acamamento e no tratamento sem manejo.

O manejo químico das coberturas favorece espécies tolerantes a herbicidas a se sobressaírem no ambiente.

\section{Referências}

Balbinot Junior, A.A.; Moraes, A.; Backes, R.L. Efeito de coberturas de inverno e sua época de manejo sobre a infestação de plantas daninhas na cultura de milho. Planta Daninha, v.25, n.3, p.473-480,

2007.
http://dx.doi.org/10.1590/S0100835820070003 00006.

Borges, W.L.B.; Freitas, R.S.; Mateus, G.P.; Sá, M.E.; Alves, M.C. Supressão de plantas daninhas utilizando plantas de cobertura do solo. Planta Daninha, v.32, n.4, p.755-763, 2014. http:// dx.doi.org/10.1590/S010083582014000400010 .

Concenço, G.; Tomazi, M.; Correia, I.V.T.; Santos, S.A.; Galon, L. Phytosociological surveys: tools for weed science? Planta Daninha, v.31, n.2,

p.469-482，2013. http://dx.doi.org/10.1590/ S0100-83582013000200025.

Cutti, L.; Lamego, F.P.; Aguiar, A.C.M.D.; Kaspary, T.E.; Rigon, C.A.G. Winter cover crops on weed infestation and maize yield. Revista Caatinga, v.29, n.4, p.885-891, 2016. http:// dx.doi.org/10.1590/198321252016v29n413rc.

Hoshino, A.T.; Hata, F.T.; Aquino, G.S.; Menezes Junior, A.O.; Ventura, M.U.; Conti Medina, C. Mulching with sugarcane straw reduces weed density in sugarcane field. International Journal of Agriculture and Biology, v.19, n.1, p.121-124, 2017. http://dx.doi.org/10.17957/IJAB/15.0252.

INMET - Instituto Nacional de Meteorologia. Disponível em: <www.inmet.gov.br>. Acesso em: 10 jan. 2017.

Kissmann, K.G.; Groth, D. Plantas infestantes e nocivas. São Paulo: Basf, 1995. Tomo II.

Kissmann, K.G.; Groth, D. Plantas infestantes e nocivas. São Paulo: Basf, 1997. Tomo I.

Kissmann, K.G.; Groth, D. Plantas infestantes e nocivas. São Paulo: Basf, 1999. Tomo III.

Lamego, F.P.; Caratti, F.C.; Reinehr, M.; Gallon, M.; Santi, A.L.; Basso, C.J. Potencial de supressão de plantas daninhas por plantas de 
cobertura de verão. Comunicata Scientiae, v.6, n.1, p. $97105,2015$.

Lima, S.F.; Timossi, P.C.; Almeida, D.P.; Da Silva, U.R. Fitossociologia de plantas daninhas em convivência com plantas de cobertura. Revista Caatinga, v.27, n.2, p.37-47, 2014.

Maciel, C.D.G.; Poletine, J.P.; Oliveira Neto, A.M.; Guerra, N.; Justiniano, W. Levantamento fitossociológico de plantas daninhas em cafezal orgânico. Bragantia, v.69, n.3, p.631-636, 2010. http:// dx.doi.org/10.1590/S000687052010000300015.

Martins, D.; Gonçalves, C.G.; Silva Junior, A.C. Coberturas mortas de inverno e controle químico sobre plantas daninhas na cultura do milho. Revista Ciência Agronômica, v.47, n.4, p.649-657, 2016.

Monquero, P.A.; Amaral, L.R.; Inácio, E.M.; Brunhara, J.P.; Binha, D.P.; Silva, P.V.; Silva, A.C. Efeito de adubos verdes na supressão de espécies de plantas daninhas. Planta Daninha, $\begin{array}{llll}\text { v.27, } & \text { n.1, } & \text { p.85-95, } & \end{array}$ http://dx.doi.org/10.1590/ S0100-83582009000100012.

Moraes, P.V.D.; Agostinetto, D.; Vignolo, G.K.; Santos, L.S.; Panozzo, L.E. Manejo de plantas de cobertura no controle de plantas daninhas na cultura do milho. Planta Daninha, v.27, n.2, p.289-296, 2009. http://dx.doi.org/10.1590/ S0100-83582009000200011.

Moreira, M.L.; Melo, M.S.C.; Carvalho, S.J.P.; Christoffoleti, P.J. Crescimento diferencial de biótipos de Conyza spp. resistente e suscetível ao herbicida glifosato. Bragantia, v.69, n.3, p.591-598, 2010. http://dx.doi.org/10.1590/ S0006-87052010000300010.

Mueller-Dombois, D.; Ellenberg, H. Aims and methods of vegetation ecology. New York: John Wiley e Sons, 1974. 547p.
Oliveira Neto, A.M.; Guerra, N.; Dan, H.D.A.; Braz, G.B.P.; Jumes, T.M.C.; Santos, G.; et al. Manejo de Conyza bonariensis com glyphosate+ 2, 4-D e amônio-glufosinate em função do estádio de desenvolvimento. Revista Brasileira de Herbicidas, v.9, n.3, p.73-80, 2010. http://dx.doi. org/10.7824/rbh.v9i3.87.

Pacheco, L.P.; Petter, F.A.; Soares, L.S.; Silva, R.F.; Oliveira, J.B.S. Sistemas de produção no controle de plantas daninhas em culturas anuais no Cerrado Piauiense. Revista Ciência Agronômica, v.47, n.3, p.500-508, 2016. http:// dx.doi.org/10.5935/1806-6690.20160060.

Parreira, M.C.; Cardozo, N.P.; Giancotti, P.R.; Alves, P.L. Superação de dormência e influência dos fatores ambientais na germinação de sementes de Spermacoce latifolia. Agrária, v.6, n.3, p.427431, 2011. http://dx.doi.org/10.5039/agraria. v6i3a1031.

Santos, W.F.; Procópio, S.O.; Silva, A.G.; Fernandes, M.F.; Barroso, A.L.L. Influência do herbicida glyphosate na comunidade de plantas daninhas na região agrícola de Rio Verde, Goiás. Revista Brasileira de Herbicidas, v.14, n.1, p.1-14, 2015. http://dx.doi.org/10.7824/rbh.v14i1.303.

Santos, W.F.; Procópio, S.O.; Silva, A.G.; Fernandes, M.F.; Barroso, A.L.L. Weed phytosociological and floristic survey in agricultural areas of southwestern Goiás region. Planta Daninha, v.34, n.1, p.65-80, 2016. http://dx.doi.org/10.1590/ S0100-83582016340100007.

Sodré Filho, J.; Carmona, R.; Cardoso, A.N.; Carvalho, A.M. Culturas de sucessão ao milho na dinâmica populacional de plantas daninhas. Scientia Agraria, v.9, n.1, p.7-14, 2008.

Tironi, S.P.; Galon, L.; Silva, A.F.; Fialho, C.M.T.; Rocha, P.R.R.; Faria, A.T.; et al. Época de emergência de azevém e nabo sobre a 
habilidade competitiva da cultura da cevada. Ciência Rural, v.44, n.9, p.1527-1533, 2014. http://dx.doi. org/10.1590/0103$8478 \mathrm{cr} 20131633$.

Viola, R.; Benin, G.; Cassol, L.C.; Pinnow, C.; Flores, M.F.; Bornhofen, E. Adubação verde e nitrogenada na cultura do trigo em plantio direto. Bragantia, v.72, n.1, p.90-100, 2013. http:// dx.doi.org/10.1590/S000687052013005000013. 